\title{
A Novel Economic Dispatch in Power Grids Based on Enhanced Firework Algorithm
}

\author{
Iman Niazazari, Oveis Asgari Gashteroodkhani, and Amir Niaz Azari
}

\begin{abstract}
This paper proposes a novel single objective optimization technique for economic dispatch (ED) in power grids. This new technique is developed based on firework algorithm (FWA) and is implemented in the IEEE 24 bus reliability test system. In this paper, the single-objective enhanced fireworks (EFWA) is developed to find the economic operating condition to minimize the generation cost. This method is a swarm intelligence algorithm that solves a singleobjective optimization problem much faster than other wellknown algorithms such as genetic algorithm (GA). The experimental results show that the proposed EFWA method is indeed capable of obtaining higher quality solutions efficiently in ED problems.
\end{abstract}

Index Terms - Economic dispatch, enhanced firework algorithm, genetic algorithm, optimization

\section{INTRODUCTION}

Optimization problems are one of the most important problems in power system planning and operation. Economic dispatch (ED) problem is probably the most widespread use of optimization in power systems. Its purpose is the minimization of the overall generation cost with respect to multiple constraints. The output of ED gives the optimal allocation of the power generated by each generator [1]. The cost function of generating units is modeled in numerous ways [2-5]. As the complexity of the model and the number of generating unit increases the difficulty of the problem increases especially in the presence of renewable energy integration [6-7]. It is usually assumed the cost function of the generators are quadratic function [8].

Several methods for solving ED problems have been proposed so far. The optimization methods for solving the problem mostly include classical mathematical techniques [912] or evolutionary techniques [13-17]. The mathematical optimization methods such as linear programming and quadratic programming are usually susceptible to the starting point and may get stuck in the local minima or even diverge [18]. However, recently evolutionary techniques have become very popular in the optimization problems in power systems [19]. Optimization techniques such as genetic algorithms (GA), imperialistic competitive algorithm (ICA) and particle swarm optimization (PSO) have been successfully used to solve power optimization problems such as loss minimization, fault location estimation, and determining the number of protective and devices in power systems [20-23]. In [20], the authors utilized GA as a scenario reduction tool to implement a multi-objective optimization problem for loss minimization under DGs' uncertainty. In [21], the authors propose a new application of ICA for fault

Iman Niazazari and Oveis Asgari Gashteroodkhani are with the Department of Electrical and Biomedical Engineering, University of Nevada, Reno, NV 89577 USA (e-mail: niazazari@nevada.unr.edu). estimation in a power system that has high accuracy in the estimation even for very complicated systems. Furthermore, based on [23], it has been shown that the GA is a powerful tool in the optimal allocation of protective and control devices in a smart grid in order to make the grid's self-healing characteristic reinforced to be able to restore as many interrupted loads as possible in the least possible time. GA methods proved to be most successful in solving the power system optimization problems; however, they do not perform very well when the problem parameters are highly correlated and they tend to fail in finding the global optimum [24-25].

Firework algorithm (FWA) is one of the evolutionary optimization methods that recently become very popular [2629]. It is first introduced by Ying Tan and Yuanchun Zhu, as a swarm based evolutionary algorithms [30]. The FWA can generate high-quality solutions within shorter calculation time and stable convergence characteristic than other stochastic methods. Zheng et al. presented a modified form of FWA called enhanced firework algorithm (EFWA) to improve the performance of FWA [31].

In this paper, an EFWA method for solving the ED problem in power system is proposed. The performance of the proposed method was validated on the IEEE 24 bus test reliability system, as compared with the GA method in the solution quality and computation efficiency. The rest of this paper is organized as follows. In section 2, the problem formulation is presented. Section 3 introduces the EFWA. Section 4 presents the simulation results followed by the conclusion in Section 5.

\section{PROBLEM FormULATION}

The objective of ED is to find the optimal output power of generating units to supply the system load demand while satisfying system constraints. It is a subset of the unit commitment problem and the optimal values of generators power are determined based on scheduled power of each generating units at each period of operation [3]. It is customary to assume a quadratic cost function for the generating units [32]. Due to the quadratic form of the cost function, the ED problem is a non-linear optimization programming. In addition, the generating power of each generator should lie between the maximum and minimum limits represented. Therefore, the problem can be formulated as follows:

The total fuel cost function is formulated as follows:

$$
\min f=\sum_{\mathrm{t}=1}^{\mathrm{T}}\left[\sum_{\mathrm{i}=1}^{n} \mathrm{~F}_{\mathrm{i}}^{\mathrm{t}}\left(\mathrm{P}_{\mathrm{i}}^{\mathrm{t}}\right)\right]
$$

where $\mathrm{F}_{\mathrm{i}}^{\mathrm{t}}$ is the total fuel cost for the $i^{\text {th }}$ generator (in $\$ / \mathrm{h}$ ) at time $t$, which is defined by

Amir Niaz Azari is with the Department of Electrical Engineering, Azad University, Sari, Iran. 


$$
\mathrm{F}_{\mathrm{i}}^{\mathrm{t}}\left(\mathrm{P}_{\mathrm{i}}^{\mathrm{t}}\right)=a_{i} \mathrm{P}_{\mathrm{i}}^{\mathrm{t}^{2}}+b_{i} \mathrm{P}_{\mathrm{i}}^{\mathrm{t}}+c_{i}
$$

where $\mathrm{a}_{\mathrm{i}}, \mathrm{b}_{\mathrm{i}}$, and $\mathrm{c}_{\mathrm{i}}$ are cost coefficients of $i^{\text {th }}$ generator.

Two constraints need to be satisfied as well:

Equality constraint: The generators powers should be the same as the load consumption, therefore,

$$
\left(\sum_{i=1}^{n} P_{i}^{t}\right)-P_{D}^{t}=0
$$

where $\mathrm{P}_{\mathrm{i}}^{\mathrm{t}}$ is the power of $i^{\text {th }}$ generator (in MW) at time $t, \mathrm{n}$ is the number of generating units in the system, $P_{D}^{t}$ is the system's total demand (in MW) at time t.

Inequality constraint: the generating units' power should stay in an acceptable range, therefore,

$$
\mathrm{P}_{\mathrm{i}}^{\min } \leq \mathrm{P}_{\mathrm{i}}^{\mathrm{t}} \leq \mathrm{P}_{\mathrm{i}}^{\max }
$$

where $\mathrm{P}_{\mathrm{i}}^{\min }$ and $\mathrm{P}_{\mathrm{i}}^{\max }$ are, the minimum and maximum power of $i^{\text {th }}$ generating unit (in MW).

\section{ENHANCED FIREWORK ALGORITHM}

The firework algorithm (FWA) is developed by the idea of the fireworks explosion. When a firework is set off, a number of sparks are generated around the firework. In summary, in this algorithm, a number of fireworks generated as individuals, and in each generation, after the explosion of these fireworks their sparks search the local space to find the optimum location and at the end of each iteration the best locations are selected for the next generation. This process is carried on until the stopping criterion is met and the optimum location is found.

It is reasonable that fireworks which are closer to the optimal solutions should have the permission to generate more sparks, and with less amplitude compared to the ones which are far away from the optimal solutions. Similar to real-life experience, most of the sparks tend to explode around the firework. However, there is a chance that some of those sparks explode far away from the firework. We call the former regular/uniform sparks, and the latter mutation/Gaussian sparks. The mutation sparks are necessary when the optimization process is stuck in a local minimum. Fig.1 shows three different fireworks with corresponding sparks.

There are some issues related to FWA that needs to be addressed. For instance, its performance worsens when it is applied to shifted functions. It means that with increasing the distance between objective function optimum and origin of the search space the performance of the algorithm is affected. In addition, FWA has a high computational cost per iteration, with respect to other evolutionary algorithms. To address these issues, four major improvements of FWA are proposed in [31]: (i) a new explosion amplitude check Eq. (7), (ii) a new way of generating regular sparks Eq. (10), (iii) a new way of generating mutation sparks Eq. (11), and (iv) a new mapping strategy for out of bounds sparks Eq. (12). In addition, a randomly based selection criterion for choosing the next iteration population is suggested as well. However, after comparing the results with the original FWA, the authors have decided to stick to the distance based selection strategy as presented in the original work [30]. The flowchart of the EFWA is presented in Fig. 2. The algorithm formulations are presented as follows:

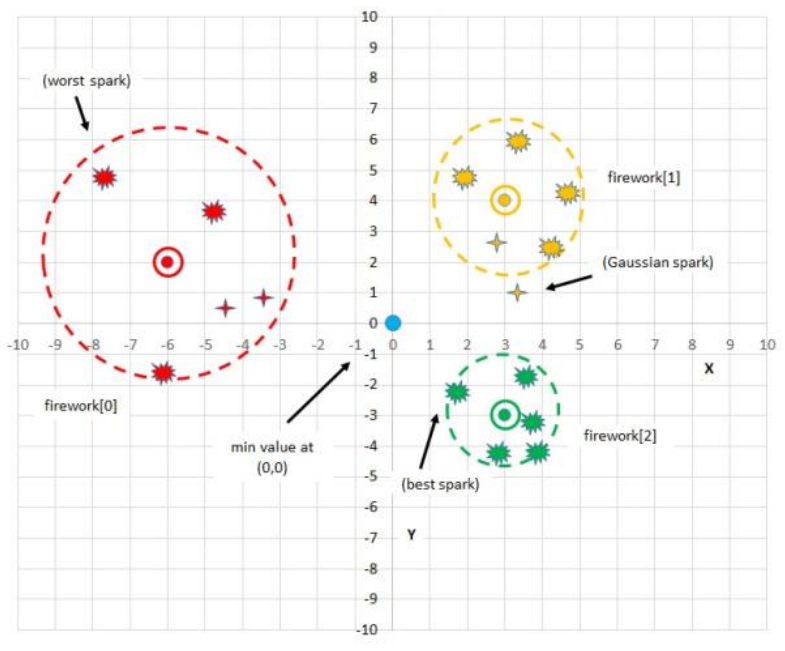

Fig.1. Scattering of different types of fireworks

The number of generated sparks and the explosion amplitude for each firework can be acquired by (5):

$$
N_{i}=\widehat{N} \times \frac{f_{\max }-f\left(x_{i}\right)+\varepsilon}{\sum_{i=1}^{N}\left(f_{\max }-f\left(x_{i}\right)\right)+\varepsilon}
$$

where $\widehat{\mathrm{N}}$ is a constant to control the number of explosion sparks, and $\varepsilon$ is a small constant to prevent the zero-divisionerror. To limit the number of generated sparks in a controllable range, $\mathrm{N}_{\mathrm{i}}$ is bound according to (6):

$$
\mathrm{N}_{\mathrm{i}}=\left\{\begin{array}{lc}
\mathrm{N}_{\max } & \text { if } \mathrm{N}_{\mathrm{i}}>\mathrm{N}_{\max } \\
\mathrm{N}_{\min } & \text { if } \mathrm{N}_{\mathrm{i}}<\mathrm{N}_{\min } \\
\operatorname{round}\left(\mathrm{N}_{\mathrm{i}}\right) & \text { otherwise }
\end{array}\right.
$$

To calculate the amplitude of the generated sparks it is noticed that it is better that in the early stage of the search, the amplitude is set to a higher value in order to facilitate exploration, and as we go along the amplitude is decreased to allow for better exploitation capabilities around good locations. Therefore, the amplitude is formulated as (7)

$$
A_{i}=\left\{\begin{array}{l}
A_{\min } \text { if } A_{i}<A_{\min } \\
A_{i} \quad \text { otherwise }
\end{array}\right.
$$

where $A_{i}$ is calculated as

$$
A_{i}=\widehat{A} \times \frac{f\left(x_{i}\right)-f_{\text {min }}+\varepsilon}{\sum_{i=1}^{N}\left(f\left(x_{i}\right)-f_{\min }\right)+\varepsilon}
$$

where $\widehat{A}$ is a constant to control the number of explosion sparks. and $\mathrm{A}_{\min }$ is calculated using a non-linear decreasing function as

$$
A_{\text {min }}=A_{\text {init }}-\frac{A_{\text {init }}-A_{\text {final }}}{t_{\max }} \sqrt{\left(2 \times t_{\max }-t\right) t}
$$

where $A_{\text {init }}$ and $A_{\text {final }}$ are the initial and final minimum explosion amplitude, respectively, and $t$ and $t_{\max }$ are the current and maximum number of iterations, respectively. 


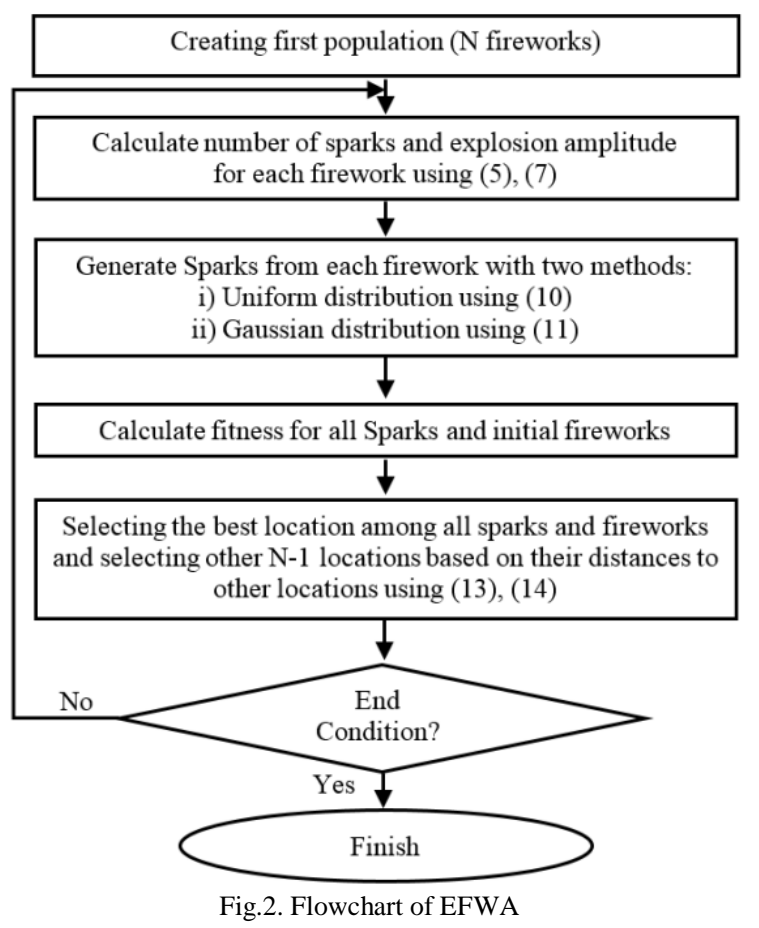

After finding the number of sparks and amplitude of each firework, it is time to determine how the sparks are distributed in the space. The location of each spark is determined in two ways:

For most of the sparks, the regular sparks, the location of sparks are obtained with a uniform function displacement with respect to the firework location. i.e.:

$$
\mathrm{X}_{\mathrm{i}}^{\prime \mathrm{k}}=\mathrm{X}_{\mathrm{i}}^{\mathrm{k}}+\mathrm{A}_{\mathrm{i}} \times \operatorname{rand}(-1,1)
$$

Where $\mathrm{k}$ shows the direction of $\mathrm{k}$.

In order to keep the diversity of the population, a few numbers of sparks, mutation sparks, are distributed with a Gaussian distribution, i.e.:

$$
\mathrm{X}_{\mathrm{i}}^{\prime \mathrm{k}}=\mathrm{X}_{\mathrm{i}}^{\mathrm{k}}+\left(\mathrm{X}_{\mathrm{B}}^{\mathrm{k}}-\mathrm{X}_{\mathrm{i}}^{\mathrm{k}}\right) \times \mathrm{N}(0,1)
$$

where $X_{B}$ is the position of the best firework found so far.

It should be noted that if the spark location is dropped out of the search area, it is mapped to another location in the area using (12).

$$
\mathrm{X}_{\mathrm{i}}^{\mathrm{k}}=\mathrm{X}_{\text {min }}^{\mathrm{k}}+\left(\mathrm{X}_{\text {max }}^{\mathrm{k}}-\mathrm{X}_{\min }^{\mathrm{k}}\right) \times \operatorname{rand}(0,1)
$$

At the end of each iteration, $\mathrm{N}$ locations are chosen for the next iteration. All original fireworks along with all regular and mutation sparks can be chosen for the next iteration. The current best location is always retained for the next iterations. The remaining $\mathrm{N}-1$ locations are selected based on a distance-based selection operator to improve the diversity in the population. For location $\mathrm{X}_{\mathrm{i}}$, the selection probability $\mathrm{p}$ is calculated by

$$
\begin{gathered}
\mathrm{p}\left(\mathrm{X}_{\mathrm{i}}\right)=\frac{\mathrm{R}\left(\mathrm{X}_{\mathrm{i}}\right)}{\sum_{j \in k} \mathrm{R}\left(\mathrm{X}_{\mathrm{j}}\right)} \\
\mathrm{R}\left(\mathrm{X}_{\mathrm{i}}\right)=\sum_{j \in k} \mathrm{~d}\left(\mathrm{X}_{\mathrm{i}}, \mathrm{X}_{\mathrm{j}}\right)=\sum_{j \in k}\left\|\mathrm{X}_{\mathrm{i}}-\mathrm{X}_{\mathrm{j}}\right\|
\end{gathered}
$$

where $\mathrm{K}$ is the entire set of original fireworks and both types of sparks except for the best location. Consequently,

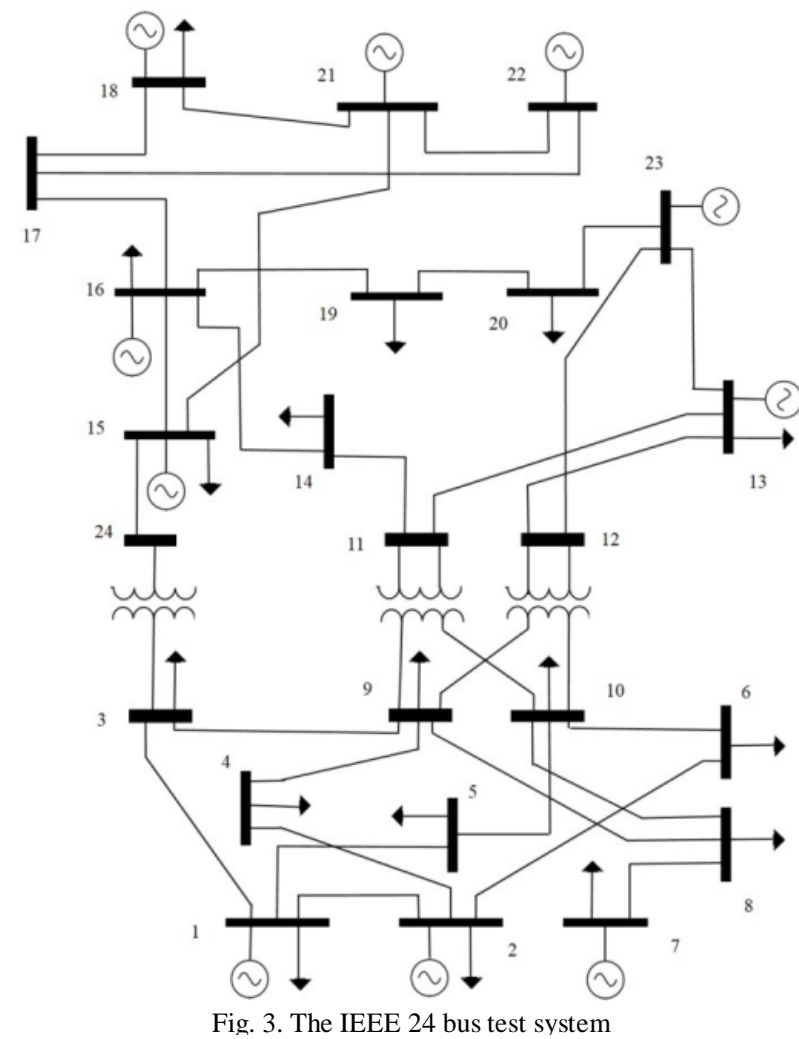

fireworks or sparks in low crowded regions will have a higher chance to be chosen for the next iteration than fireworks or sparks in crowded regions [30].

\section{SimUlations AND RESUlts}

\section{A. Case Study}

To verify the efficiency of the proposed EFWA method, it has been applied to the ED problem in the IEEE 24 bus reliability test system as shown in Fig. 3. Table I demonstrates the units generating capacities along with their cost coefficients [31]. There are 12 units in the system, with two nuclear, five coal/stream, one coal $/ 3$ stream, three oil/stream, and one hydro unit. The total generation capacity of the system is $3325 \mathrm{MW}$. The total demand power in 24 hours is presented in Table II [32]. The tuning parameters for EFWA are determined using extensive trial and error: the $\mathrm{N}_{\min }, \mathrm{N}_{\max }, \widehat{\mathrm{N}}$ are selected as 10,40 , and 300 , respectively.

Also, $\mathrm{A}_{\text {final }}$ is set to 0.01 and $\mathrm{A}_{\text {init }}$ is set to the minimum of difference between locations in all directions. Noted that for all the simulations in this paper, the experimental platform is: Win7; Intel with CPU X5482 2×3.2 GHz; RAM 16 GB.

\section{B. Discussions}

The simulation is conducted with both EFWA and GA methods. Table III compares two methods in terms of simulation time. This table only shows some time steps of the day as the representatives of all hours, but the last row of the table shows the total time needed for each method to find the optimal solution for the entire scheduling horizon, i.e., 24 hours. As it is observed from the Table, although GA needs less computational time for each iteration, it requires much more number of iteration and subsequently computational time to find the true optimal solution compared to EFWA. 
TABLE I. GENERATING UNIT CAPACITY AND COEFFICIENTS

\begin{tabular}{|c|c|c|c|c|c}
\hline Unit & $\begin{array}{c}\mathrm{P}_{\max } \\
{[\mathrm{MW}]}\end{array}$ & $\begin{array}{c}\mathrm{P}_{\min } \\
{[\mathrm{MW}]}\end{array}$ & $\begin{array}{c}\mathrm{a} \\
{\left[\$ / \mathrm{MW}^{2}\right]}\end{array}$ & $\begin{array}{c}\mathrm{b} \\
{[\$ / \mathrm{MW}]}\end{array}$ & $\begin{array}{c}\mathrm{c} \\
{[\$]}\end{array}$ \\
\hline 18 & 400 & 100 & 0.000213 & 4.4231 & 395.374 \\
\hline 21 & 400 & 100 & 0.000213 & 4.4231 & 395.374 \\
\hline 1 & 152 & 30.4 & 0.014142 & 16.0811 & 212.307 \\
\hline 2 & 152 & 30.4 & 0.014142 & 16.0811 & 212.307 \\
\hline $15 \mathrm{~b}$ & 155 & 54.25 & 0.008342 & 12.3883 & 382.239 \\
\hline 16 & 155 & 54.25 & 0.008342 & 12.3883 & 382.239 \\
\hline $23 \mathrm{a}$ & 310 & 108.5 & 0.008342 & 12.3883 & 382.239 \\
\hline $23 \mathrm{~b}$ & 350 & 140 & 0.004895 & 11.8495 & 665.109 \\
\hline 7 & 300 & 75 & 0.052672 & 43.6615 & 781.521 \\
\hline 13 & 591 & 206.9 & 0.00717 & 48.5804 & 832.757 \\
\hline $15 \mathrm{a}$ & 60 & 12 & 0.328412 & 56.564 & 86.3852 \\
\hline 22 & 300 & 60 & 0 & 0.001 & 0.001 \\
\hline
\end{tabular}

TABLE II. LOAD PROFILE IN 24 HOURS

\begin{tabular}{|c|c|c|c|}
\hline Hour & $\begin{array}{c}\text { System Demand } \\
{[\mathrm{MW}]}\end{array}$ & Hour & $\begin{array}{c}\text { System Demand } \\
{[\mathrm{MW}]}\end{array}$ \\
\hline 1 & 1598.252 & 13 & 2266.178 \\
\hline 2 & 1502.834 & 14 & 2266.178 \\
\hline 3 & 1431.27 & 15 & 2218.469 \\
\hline 4 & 1407.416 & 16 & 2218.469 \\
\hline 5 & 1407.416 & 17 & 2361.596 \\
\hline 6 & 1431.27 & 18 & 2385.45 \\
\hline 7 & 1765.233 & 19 & 2385.45 \\
\hline 8 & 2051.487 & 20 & 2290.032 \\
\hline 9 & 2266.178 & 21 & 2170.76 \\
\hline 10 & 2290.032 & 22 & 1979.924 \\
\hline 11 & 2290.032 & 23 & 1741.379 \\
\hline 12 & 2266.178 & 24 & 1502.834 \\
\hline
\end{tabular}

TABLE III. COMPARISON OF EFWA AND GA SPEED

\begin{tabular}{|c|c|c|c|c|}
\hline Hour & $\begin{array}{c}\text { GA } \\
\text { Time per } \\
\text { Iteration [s] }\end{array}$ & $\begin{array}{c}\text { GA } \\
\text { Total } \\
\text { Time [s] }\end{array}$ & $\begin{array}{c}\text { EFWA } \\
\text { Time per } \\
\text { Iteration [s] }\end{array}$ & $\begin{array}{c}\text { EFWA } \\
\text { Total } \\
\text { Time [s] }\end{array}$ \\
\hline 1 & 0.0312 & 6.7073 & 0.1291 & 4.0321 \\
\hline 9 & 0.0278 & 6.5945 & 0.096 & 3.7240 \\
\hline 17 & 0.0392 & 7.6738 & 0.1372 & 3.7168 \\
\hline $\begin{array}{c}\text { Whole } \\
\text { day }\end{array}$ & N/A & 189.6543 & N/A & 90.2541 \\
\hline
\end{tabular}

Moreover, the last row of the table indicates that to find the same optimal answer, the EFWA method is almost 2 times faster than GA.

Fig. 4 shows the minimum total cost for both EFWA and GA methods for the entire scheduling horizon. It is assumed that the end condition for both methods is the number of iterations which is 100 for each scheduling subintervals (i.e., each hour). Also, the number of initial population for both methods are equal to 10. As it is observed from Fig. 4, for almost all scheduling horizon, the minimum total cost related to EFWA is smaller than the one associated with GA.

Fig. 5 and Fig. 6 depict the optimal generation output of each generator at each hour using GA and EFWA methods, respectively. These figures have been plotted with the same parameters of Fig. 4. In this figure, from the darkest color to the brightest one, each color represents the scheduled power

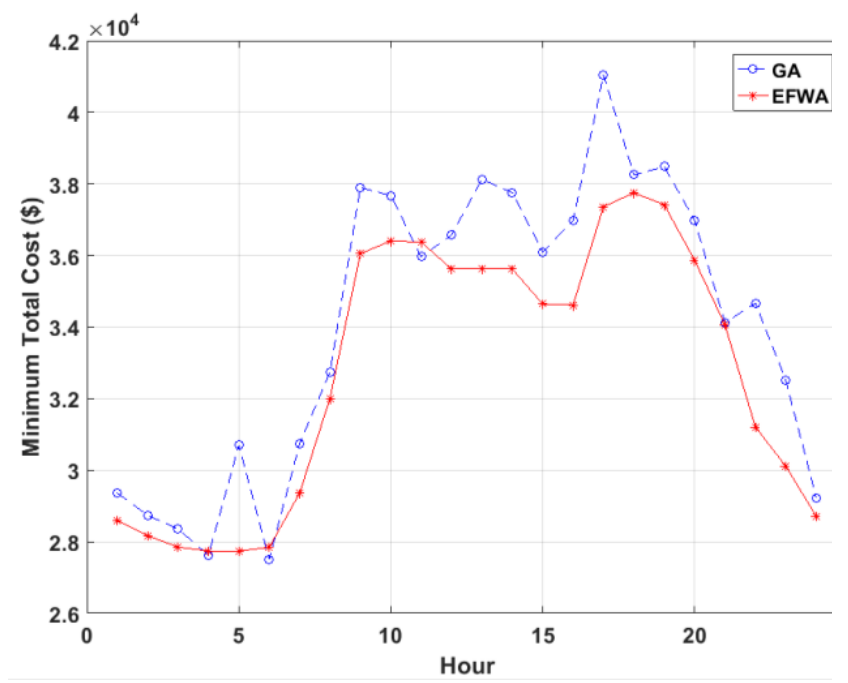

Fig. 4. minimum total cost for both EFWA \& GA methods for whole day

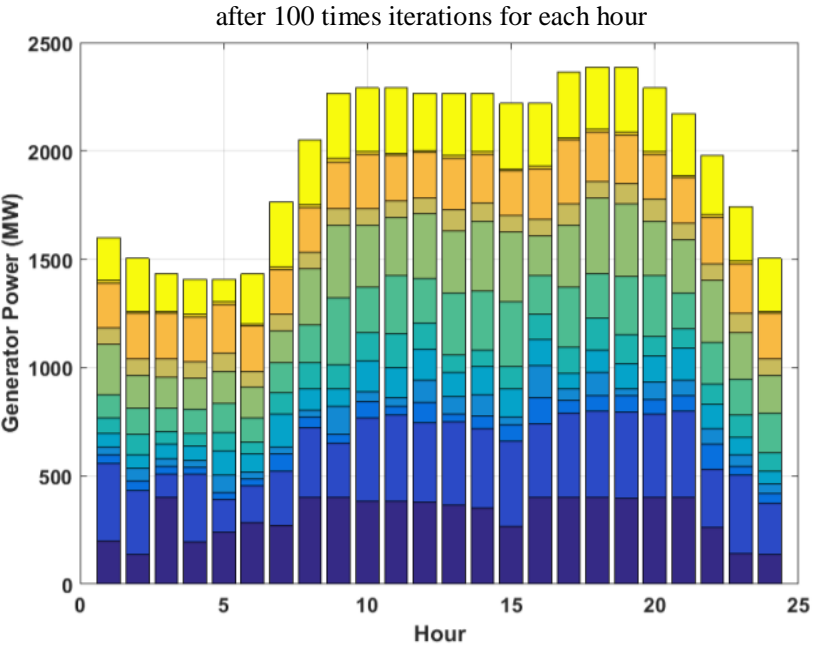

Fig. 5. optimal generation output of each generator at each hour using GA

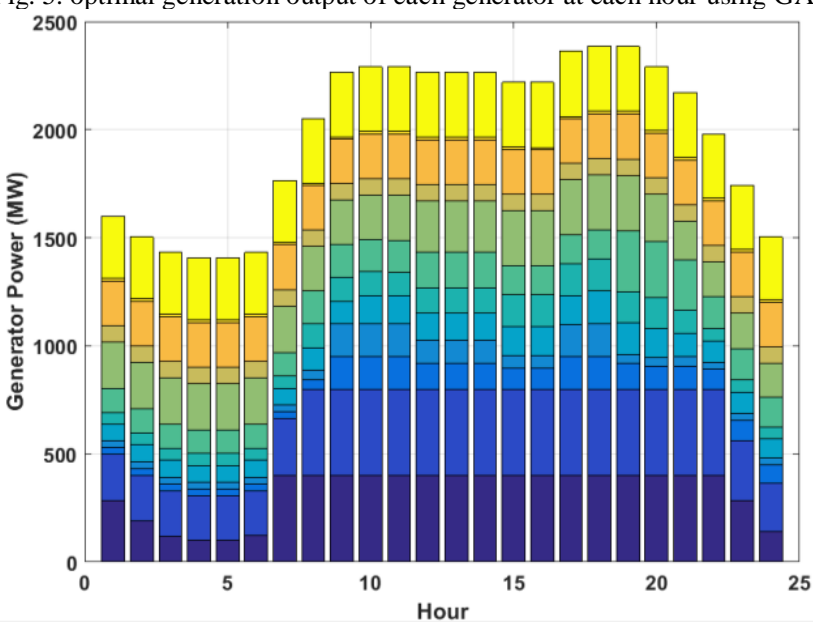

Fig. 6. optimal generation output of each generator at each hour using EFWA

generation with the sequence mentioned in Table I. Therefore, after solving the single-objective optimization by GA and EFWA methods, the best operation points for all generations are according to the ones in Fig. 5 and Fig. 6, respectively.

\section{CONCLusions}

This paper presents a new single objective optimization technique for performing economic dispatch in power networks. This new technique is developed based on real-life 
firework explosion and is called enhanced firework algorithm (EFWA). In order to validate the efficiency of the proposed EFWA method, it has been applied to the ED problem in the IEEE 24 bus reliability test system and then compared to the GA method as the benchmark. The simulation results show the superiority of EFWA to find the optimal solution with less computation time compared to GA. In addition, the simulation results validate the better performance of the EFWA method, to achieve the minimum total cost, within the certain computational time limit for each scheduling hour.

\section{REFERENCES}

[1] Hetzer, J., David, C. Y., \& Bhattarai, K. (2008). An economic dispatch model incorporating wind power. IEEE Transactions on energy conversion, 23(2), 603-611.

[2] Yang, H. T., Yang, P. C., \& Huang, C. L. (1996). Evolutionary programming based economic dispatch for units with non-smooth fuel cost functions. IEEE transactions on Power Systems, 11(1), 112118.

[3] Gaing, Z. L. (2003). Particle swarm optimization to solving the economic dispatch considering the generator constraints. IEEE transactions on power systems, 18(3), 1187-1195.

[4] Lin, C. E., \& Viviani, G. L. (1984). Hierarchical economic dispatch for piecewise quadratic cost functions. IEEE transactions on power apparatus and systems, (6), 1170-1175.

[5] Lin, W. M., Cheng, F. S., \& Tsay, M. T. (2002). An improved tabu search for economic dispatch with multiple minima. IEEE Transactions on power systems, 17(1), 108-112.

[6] Chitsazan, M. A., Fadali, M. S., \& Trzynadlowski, A. M. (2019). Wind speed and wind direction forecasting using echo state network with nonlinear functions. Renewable energy, 131, 879-889.

[7] Chitsazan, M. A., Fadali, M. S., Nelson, A. K., \& Trzynadlowski, A. M. (2017, May). Wind speed forecasting using an echo state network with nonlinear output functions. In 2017 American Control Conference (ACC) (pp. 5306-5311). IEEE.

[8] Alsumait, J. S., Sykulski, J. K., \& Al-Othman, A. K. (2010). A hybrid GA-PS-SQP method to solve power system valve-point economic dispatch problems. Applied Energy, 87(5), 1773-1781.

[9] Niazazari, I., Abyaneh, H. A., Farah, M. J., Safaei, F., \& Nafisi, H. (2014, May). Voltage profile and power factor improvement in PHEV charging station using a probabilistic model and flywheel. In 2014 19th Conference on Electrical Power Distribution Networks (EPDC) (pp. 100-105). IEEE.

[10] Coelho, L. S., \& Mariani, V. C. (2006). Combining of chaotic differential evolution and quadratic programming for economic dispatch optimization with valve-point effect. IEEE Transactions on power systems, 21(2), 989-996.

[11] S. M. M. H. N., S. Heydari, H. Mirsaeedi, A. Fereidunian, and A. R. Kian, "Optimally operating microgrids in the presence of electric vehicles and renewable energy resources," in 2015 Smart Grid Conference (SGC), Dec 2015, pp. 66-72.

[12] Zakeri, A. S., Gashteroodkhani, O. A., Niazazari, I., \& AskarianAbyaneh, H. (2019). The effect of different non-linear demand response models considering incentive and penalty on transmission expansion planning. European Journal of Electrical Engineering and Computer Science, 3(1).

[13] Abido, M. A. (2003). A novel multiobjective evolutionary algorithm for environmental/economic power dispatch. Electric power systems research, 65(1), 71-81.

[14] Noman, N., \& Iba, H. (2008). Differential evolution for economic load dispatch problems. Electric power systems research, 78(8), 1322-1331.

[15] Basu, M. (2011). Economic environmental dispatch using multiobjective differential evolution. Applied soft computing, 11(2), 2845 2853.

[16] Aranizadeh, A., Niazazari, I., \& Mirmozaffari, M. (2019). A Novel Optimal Distributed Generation Planning in Distribution Network using Cuckoo Optimization Algorithm. European Journal of Electrical Engineering and Computer Science, 3(3).

[17] Vlachogiannis, J. G., \& Lee, K. Y. (2009). Economic load dispatchA comparative study on heuristic optimization techniques with an improved coordinated aggregation-based PSO. IEEE Transactions on Power Systems, 24(2), 991-1001.

[18] Bomze, I. M., \& De Klerk, E. (2002). Solving standard quadratic optimization problems via linear, semidefinite and copositive programming. Journal of Global Optimization, 24(2), 163-185.
[19] Pindoriya, N. M., Singh, S. N., \& Lee, K. Y. (2010, July). A comprehensive survey on multi-objective evolutionary optimization in power system applications. In IEEE PES General Meeting (pp. 18). IEEE

[20] A. Abbaskhani-Davanloo, M. Amini, M. S. Modarresi, F. Jafarishiadeh, "Distribution System Reconfiguration for Loss Reduction Incorporating Load and Renewable Generation Uncertainties," 2019 IEEE Texas Power and Energy Conference (TPEC), College Station, TX, 2019.

[21] O. A. Gashteroodkhani and B. Vahidi, "Application of Imperialistic Competitive Algorithm to Fault Section Estimation Problem in Power Systems," in The International Conference in New Research of Electrical Engineering and Computer Science, Iran, Sep 2015.

[22] O. A. Gashteroodkhani, M. Majidi, M. Etezadi-Amoli, A. F. Nematollahi, B. Vahidi, "A hybrid SVM-TT transform-based method for fault location in hybrid transmission lines with underground cables" Electric Power Systems Research, vol. 170, pp. 205-214, 2019.

[23] S. Heydari, SM. Mohammadi-Hosseininejad, H. Mirsaeedi, A. Fereidunian, H. Lesani, "Simultaneous placement of control and protective devices in the presence of emergency demand response programs in smart grid," International Transactions on Electrical Energy, 2018; e2537. https://doi.org/10.1002/etep.2537

[24] D. B. Fogel, Evolutionary Computation: Toward a New Philosophy of Machine Intelligence, 2 ed. Piscataway, NJ: IEEE Press, 2000.

[25] Krishna, K., \& Murty, N. M. (1999). Genetic K-means algorithm. IEEE Transactions on Systems Man And Cybernetics-Part B: Cybernetics, 29(3), 433-439.

[26] Imran, A. M., \& Kowsalya, M. (2014). A new power system reconfiguration scheme for power loss minimization and voltage profile enhancement using fireworks algorithm. International Journal of Electrical Power \& Energy Systems, 62, 312-322.

[27] Zheng, Y. J., Song, Q., \& Chen, S. Y. (2013). Multiobjective fireworks optimization for variable-rate fertilization in oil crop production. Applied Soft Computing, 13(11), 4253-4263.

[28] Sarfi, V., Niazazari, I., \& Livani, H. (2016, September). Multiobjective fireworks optimization framework for economic emission dispatch in microgrids. In 2016 North American Power Symposium (NAPS) (pp. 1-6). IEEE.

[29] Bacanin, N., \& Tuba, M. (2015, May). Fireworks algorithm applied to constrained portfolio optimization problem. In 2015 IEEE Congress on evolutionary computation (CEC) (pp. 1242-1249). IEEE.

[30] Tan, Y. and Zhu, Y., 2010. Fireworks algorithm for optimization. Advances in swarm intelligence, pp.355-364.

[31] Zheng, S., Janecek, A. and Tan, Y., 2013, June. Enhanced fireworks algorithm. In Evolutionary Computation (CEC), 2013 IEEE Congress on (pp. 2069-2077).

[32] A. J. Wood and B. F. Wollenbergy, Power Generation, Operation, and Control. New York: Wiley, 1984.

[33] Available at http://www.pserc.cornell.edu/matpower/

[34] Available at pierrepinson.com/31761/Projects/Project2/IEEE-RTS24.pdf 